\title{
Comissões de Ética em Portugal: Velhos e Novos Desafios
}

\section{Ethics Committees in Portugal: Old and New Challenges}

João MASSANO ${ }^{1,2,3}$, Filipe Nuno ALMEIDA $\triangle^{4,5,6}$

Acta Med Port 2020 May;33(5):295-296 - https://doi.org/10.20344/amp.13709

Palavras-chave: Bioética; Códigos de Ética; Comissões de Ética; Coronavírus; Declaração de Helsínquia; Investigação Biomédica Keywords: Bioethics; Biomedical Research; Codes of Ethics; Coronavirus; Ethics Committees; Helsinki Declaration

A História tem mostrado como a autorregulação profissional não assegura o respeito da dignidade humana. Os horrores no Terceiro Reich e na Manchúria japonesa motivaram a elaboração do Código de Nuremberga, ainda assim impotente para evitar as inaceitáveis experiências de Tuskegee e de Willowbrook. ${ }^{1} \mathrm{O}$ desenvolvimento tecnológico e científico trouxe novos desafios às decisões clínicas, como o acesso a recursos limitados, ou as decisões de limitação ou suspensão terapêutica. Criaram-se Comissões de Ética (CE) para aconselhamento e regulação ética, tanto para a prática clínica como para a investigação biomédica. ${ }^{2,3}$ A Associação Médica Mundial, no mesmo encalço, elabora a Declaração de Helsínquia (1964, com posteriores emendas), que aponta os princípios éticos para a investigação médica envolvendo seres humanos. Beauchamp e Childress desenvolvem em 1979 uma bioética principialista, importante esteio para a reflexão e conduta ética, que veio a conhecer importantes aportações com a Declaração de Barcelona. ${ }^{4}$ Não questionando a relevância daqueles princípios relativamente ao respeito pela autonomia, foi nesta Declaração dedicada uma particular perspectiva e novos princípios foram agora propostos, numa tentativa de aquilatar a responsabilidade que neste século se pede no exercício ético: o da dignidade, o da integridade e o da vulnerabilidade. Nesta nova abrangência, vislumbramos, cremos, uma ética mais humanista porque atenta de forma mais clara a uma adequada resposta à fragilidade de quem aguarda um humanizado agir profissional, nas fronteiras da ciência e da técnica.

A iniciativa legislativa em Portugal tem tentado ajustar-se aos novos desafios científicos, éticos e políticos, porventura em resultado da consciencialização de decisores políticos e legisladores e para responder aos apelos das várias partes interessadas nesta temática (e.g. stakeholders). A Lei n. ${ }^{\circ}$ 21/2014 introduziu alterações na regulamentação da investigação clínica, nomeadamente no que concerne ao espaço de intervenção para a Comissão de Ética para a Investigação Clínica (CEIC) e Comissões de
Ética Competentes, a que está cometida a legitimidade de emitir pareceres sobre ensaios clínicos com medicamentos e dispositivos médicos. ${ }^{5}$

O Decreto-Lei n. ${ }^{\circ}$ 80/2018 veio ajustar a regulamentação legal das CE. ${ }^{6}$ O preâmbulo deste DL afirma como objectivo "a regulação das CE, a sua composição, constituição, competências e modo de funcionamento, dotando-as de um instrumento atualizado e clarificador das suas competências, objetivos, direitos e deveres". Esta legislação alargou a obrigatoriedade da existência de CE a todas as instituições onde se realize investigação em seres humanos. Para além das instituições de saúde públicas, privadas e sociais, agora também as instituições de ensino superior e os centros de investigação biomédica que desenvolvam investigação em seres humanos se obrigam a ter comissões de ética para a poderem realizar. Pretende-se, assim, a aprovação ética e o acompanhamento das iniciativas de investigação clínica em todas as instituições onde esta é realizada. Os Centros Académicos Clínicos podem instituir uma CE única, resultante da natural proximidade entre Centros Hospitalares e Faculdades de Medicina. A exemplo, o Centro Universitário de Medicina (Faculdade de Medicina da Universidade do Porto - Centro Hospitalar Universitário de São João) implementou já em 2011 este modelo, sendo única a CE que apoia ambas as instituições, admitindo na sua composição membros do CHUSJ e da FMUP, que aportam as diversas visões e experiências dos ambientes clínico e académico, naturalmente complementares. Ainda, a multidisciplinaridade dos membros da CE e a existência de membros externos às próprias instituições robustecem a desejada pluralidade de visões e dos valores no seio da mesma, como reflexo da própria Sociedade.

Com a legislação de 2018, as competências das CE tornaram-se mais transversais. Para além da elaboração de documentos orientadores, a sua intervenção pedagógica na comunidade é relevada, devendo destacar-se, certamente, a elaboração de pareceres que agora lhe poderão ser solicitados não só por quaisquer membros da

\footnotetext{
1. Serviço de Neurologia e Unidade de Investigação. Centro Hospitalar Universitário de São João. Porto. Portugal.

2. Departamento de Neurociências Clínicas e Saúde Mental. Faculdade de Medicina. Universidade do Porto. Porto. Portugal.

3. Unidade de Investigação e Desenvolvimento Cardiovascular (UnIC). Faculdade de Medicina. Universidade do Porto. Porto. Portugal

4. Comissão de Ética para a Saúde. Centro Hospitalar Universitário de São João e Faculdade de Medicina. Universidade do Porto. Porto. Portugal.

5. Serviço de Humanização. Centro Hospitalar Universitário de São João. Porto. Portugal.

6. Departamento de Ciências de Saúde Pública e Forenses e Educação Médica. Faculdade de Medicina. Universidade do Porto. Porto. Portugal.

$\triangle$ Autor correspondente: Filipe Nuno Almeida. falmeida@med.up.pt

Recebido: 11 de março de 2020 - Aceite: 12 de março de 2020 | Copyright $\odot$ Ordem dos Médicos 2020
} 
comunidade hospitalar, como pelos doentes ou seus representantes/familiares. Esta abrangência de actuação permitirá fomentar o respeito pelos valores éticos de forma muito mais ampla nas instituições, em prol da dignidade de quem nelas procura respostas, quantas vezes em situação de fragilidade física e mental.

A actividade das CE é cada vez mais complexa e intensa, pelo que a actual legislação previu o aumento do número de elementos das $\mathrm{CE}$ até um máximo de onze, alargamento este que, mesmo a concretizar-se, não dispensa ajustes adicionais para que se possa melhorar a capacidade de resposta que Ihes é pedida. É necessário que aos seus elementos seja concedido tempo suficiente dedicado a esta actividade, bem como condições logísticas consonantes com a intensa actividade de pesquisa e reflexão, amiúde densa e difícil, que é crucial para a apreciação dos pedidos e elaboração dos respectivos pareceres, ou outros documentos. A grande quantidade de desafios apresentados hoje às CE coloca em cima da mesa a discussão sobre a oportunidade de profissionalização de alguns dos seus membros, no que concerne a uma possível dedicação exclusiva de alguns. E esta questão não poderá certamente aguardar por uma resposta sem termo. É, na verdade, matéria crucial, atendendo ao papel que hoje as CE desenvolvem nas instituições, a um tempo respeitado e solicitado por tantos profissionais e gestores, a que se junta a possibilidade de, nas instituições de saúde, doentes e/ ou seus familiares se poderem dirigir às $C E$ solicitando pareceres. Se não ignorarmos o papel de consultoria que no exercício de efectiva proximidade das CE se experimenta, não como horizonte longínquo, mas hoje já objectivo, compreende-se a fundamental necessidade de se assegurar a formação contínua dos elementos das CE nas temáticas ligadas à bioética e outros tópicos de interesse para a sua actividade, actualmente muito diversificada e intrincada. $\mathrm{O}$ contributo legislativo é muito importante, sem dúvida, mas verdadeiramente essencial será a forma como a bioética é operacionalizada, isto é, em que terrenos se trabalha o seu desígnio reflexivo harmoniosamente plasmado nas dinâmicas operativas que são esperadas. Às cúpulas institucionais é, pois, requerida especial sensibilização para o papel

\section{REFERÊNCIAS}

1. Rothman DJ. Were Tuskegee \& Willowbrook 'Studies in Nature'? Hastings Cent Rep. 1982;12:5-7.

2. Illes J, Bird SJ. Neuroethics: a modern context for ethics in neuroscience. Trends Neurosci. 2006:29;511-7.

3. Hajibabaee F, Joolaee S, Cheraghi M, Salari P, Rodney P. Hospital/ clinical ethics committees' notion: an overview. J Med Ethics Hist Med. 2016;9:17.

4. Kemp P, Rendtorff JD. The Barcelona Declaration: towards an integrated approach to basic ethic principles. Synth Philos. 2008;23:239-51.

5. Decreto-Lei n. ${ }^{\circ} 21 / 2014$, Diário da República, I Série, $n .^{\circ} 75(2014 / 04 / 16)$. p. 2450- 65 alterado pelo Decreto-Lei n. ${ }^{\circ} 73 / 2015$, Diário da República, I Série, n. ${ }^{\circ} 144$ (2015/07/27). p. 5027-8.

6. Decreto-Lei n. ${ }^{\circ} 80 / 2018$, Diário da República, I Série, n. ${ }^{\circ} 198$ particularmente importante que desempenham na criação das condições de trabalho das CE.

Assistimos diariamente à vertiginosa evolução do mundo e da sociedade, com avanços tecnológicos por vezes inimagináveis, descobertas científicas mais ou menos espantosas, como a Inteligência Artificial, machine learning, wearables e big data, apenas para mencionar alguns. ${ }^{7} \mathrm{~A}$ reboque do progresso surgem novos problemas e desafios, que impactam na mente e no quotidiano de cada um de nós, como a procriação medicamente assistida, as decisões no início e no fim de vida, o envelhecimento, a protecção de dados, a própria gestão institucional, também ela não alheia à atenção à equidade. Velhas e novas questões que, como seria de esperar, reverberam também nas questões que hoje são colocadas às $\mathrm{CE}$.

Por outro lado, os velhos problemas permanecerão, sendo provável que alguns assumam no futuro uma dimensão muito maior do que até aqui. $A$ inovação nos cuidados de saúde, tanto no diagnóstico como na terapêutica, nomeadamente das doenças oncológicas e neurodegenerativas, cada vez mais prevalentes no contexto do enveIhecimento da população, pressionará de forma crescente os sistemas de saúde. ${ }^{8}$ Numa sociedade cada vez mais envelhecida, doente e exigente, os recursos económicos tenderão a diminuir. Surgirão mais e novos conflitos e dificuldades na observância dos vários princípios éticos. $\mathrm{Na}$ actual pandemia pelo vírus SARS-Cov-2, tomar decisões face aos recursos insuficientes para as enormes demandas assistenciais, como entender a autonomia no premente respeito pela dignidade humana e na atenção necessária à sociabilidade e subsidiariedade proposta por Sgreccia, ${ }^{9}$ no contexto da extrema vulnerabilidade humana, são reptos muito complexos e exigentes à reflexão ética que se impõe fazer. As CE terão de estar à altura do desafio e deverão revelar-se um sólido farol para toda a sociedade.

\section{FONTES DE FINANCIAMENTO}

Este trabalho não recebeu qualquer tipo de financiamento ou subsídio por entidades do sector público ou privado.

(2018/10/15). P. 4965- 70

7. Academy for Life. Rome Call for All Ethics. Rome, February 28th 2020 [consultado Março 12 2020]. Disponível em: http://www.academyforlife. va/content/dam/pav/documenti\%20pdf/2020/CALL\%2028\%20febbraio/ AI\%20Rome\%20Call\%20x\%20firma_DEF_DEF_.pdf.

8. Araújo R, Massano J. O acordar da mente: a necessidade de preparação para os tratamentos inovadores da Doença de Alzheimer. Observador, 25 Janeiro 2020. [consultado Março 12 2020]. Disponível em https:// observador.pt/opiniao/o-acordar-da-mente-a-necessidade-depreparacao-para-os-tratamentos-inovadores-da-doenca-de-alzheimer/.

9. Sgreccia E. Manual de Bioética: Fundamentos e ética biomédica. Parede: Principia Editora; 2009. 